\title{
落込み充塡における粉末充填挙動の可視化
}

\author{
近藤 幹夫放, 竹本 恵英方2

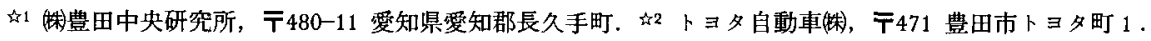

\section{Visualization of Powder Behavior for Gravity Filling}

\author{
Mikio Kondoh ${ }^{\text {‘ } 1}$ and Shigehide Takemoto ${ }^{\not \zeta 2}$ \\ t1 Toyota Central Research \& Development Laboratories Inc., Nagakute-cho Aichi-gun, Aichi 480-11. \\ t5 Toyota Motor Corporation, 1 Toyota-cho, Toyota 471.
}

Received July 24, 1996

\section{SYNOPSIS}

It is essential for improving the dimensional tolerance of complex $\mathrm{P} / \mathrm{M}$ parts to uniformly fill powders in a die cavity. This study is aimed at clarifying the powder behavior in filling the die cavity. A visual apparatus was developed for observing the powder behavior. Using this apparatus, the effects of the die cavity shape and feed-shoe speed on the filling behavior, density and particle size segregation of filled powders were investigated for gravity filling of atomized iron powders.

It is clarified that the particle size segregation in filling occurs independently on the shoe speed and die cavity shape. Coarse particles segregate in the place where the powder falls along the angle of repose, while fine particles segregate in the thin-walled part and the position where the empty space finally disappears.

\section{KEY WORDS}

dimensional tolerance, gravity filling, filling behavior, particle size segregation

\section{1 緒 言}

自動車用の焼結部品は, 薄肉で大きな段差を有す る複雑な形状のものが多い.そのために，一回の成 形と焼結だけでは寸法精度が確保できず, 後加工と してサイジングや切削加工が必要となる。低コスト 化のため，できるだけ後加工を省略するには，焼結 部品の寸法精度を向上させる必要がある。法精度 の问上にとって, 粉末を金型キャビティへ均一に充 填することが成形技術の重要な課題の一つである. しかし，粉末充填に関する研究は少なく，その挙動 には不明な点が多い1，2．

本研究では, 新しく考案した充填挙動の可視化装 置を用いて，落込み充填に扔ける粉末の充填挙動， 密度，粒度偏析などに及はす粉末特性，キャビティ 形状，粉箱移動速度などの影響について調べた。

\section{2 実験方法}

\section{1 粉末充填可視化装置と試験条件}

考案した粉末立填可視化装置の外観をPhoto.1に 示す。この装置は粉箱とキャビティ及び制御盤から 構成されている、粉箱と型の前面は, 粉末の動きを 観察できるように透明なアクリル板で構成してあ る. キャビティ形状は，3分割した下パンチのそれ ぞれの深さと厚さを変えることにより,種々に変化 させた、実験に用いたキャビティ形状を Fig.lに示 す. 溥肉の矩形キャビティは幅 $20 \mathrm{~mm}$, 深さ $40 \mathrm{~mm}$ として厚さ（t）を $1 ， 2 ， 5 \mathrm{~mm}$ と変えた。複雑な形 状のキャビティは中央部に段差のある $1 \mathrm{~mm} の$ 薄肉 部を有し，両側に厚肉部があるものとした，粉箱は 横方向と正面からそれぞれ移動させ，移動速度 (V) は10～60 mm/sまで変えた. 粉末の无填過程は 
Feed-shoe for back and forth direction

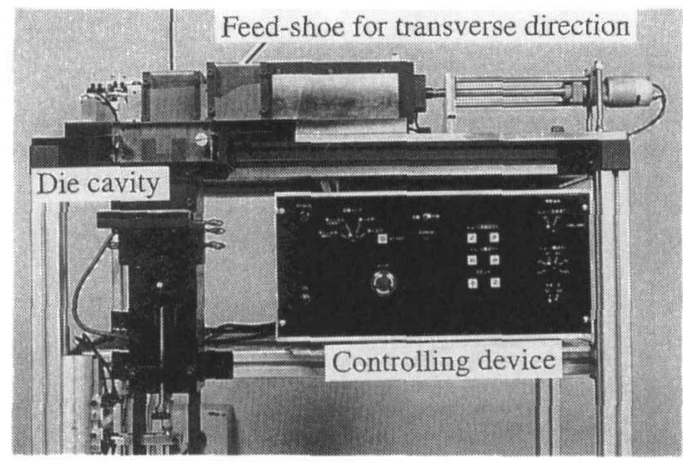

Photo. 1 Appearance of visual apparatus.

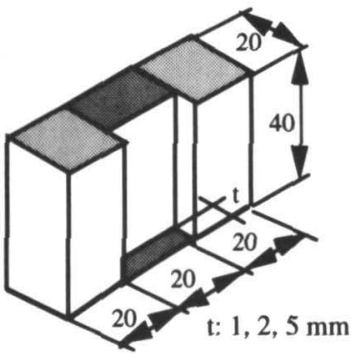

Rectangular cavity

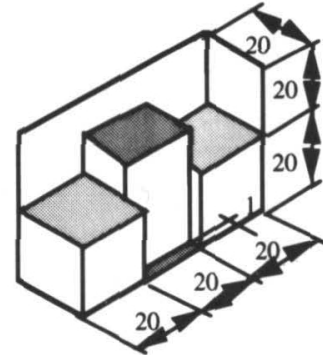

Complex cavity
Fig.1 Schematic illustration of die cavities

ビデオカメラで, 粉末の充填状態はCCDカメラでそ れぞれ撮影した。

\section{2 使用粉末}

原料粉末は, ヘガネス社製の噴霧鉄粉ASC100-29 とCuを $10 \%$ 拡散合金化したDISTALOY-ACu，日本 黒鉛社製の黒鉛粉 J-CPB である，潤滑剤は日本油脂 製のステアリン酸要鉛（ZnSt.）である。実験には $\mathrm{Fe}+0.3,0.8,1.2 \% \mathrm{ZnSt}$.の 3 種類, $\mathrm{Fe}$ $2 \% \mathrm{Cu}+0.8 \% \mathrm{ZnSt}$., $\mathrm{Fe}-2 \% \mathrm{Cu}-1 \% \mathrm{C}+0.8 \% \mathrm{ZnSt}$. 混合粉 及びへガネス社製の P r e - m i x 粉 $(\mathrm{Fe}-2 \% \mathrm{Cu}$ $0.8 \% \mathrm{C}+0.8 \%$ Lub.) を用いた．充填状態のミクロ観察 には, $\mathrm{Fe}-2 \% \mathrm{Cu}+0.8 \% \mathrm{ZnSt}$. 混合粉を用いた。

使用した粉末の特性をTable 1 に示す. 各種粉末の 限界流出径(Min. Dia. ) は, オリフィス径を $\phi 0.5$

Table 1 Characteristics of powders used in this experiment

\begin{tabular}{|c|c|c|c|}
\hline Powder & $\begin{array}{c}\text { A.D. } \\
\left(\mathrm{g} / \mathrm{cm}^{3}\right)\end{array}$ & $\begin{array}{c}\text { Flow Rate } \\
(\mathrm{s} / 50 \mathrm{~g})\end{array}$ & $\begin{array}{c}\text { Min. Dia. } \\
(\mathrm{mm})\end{array}$ \\
\hline $\mathrm{Fe}+0.3 \%$ ZnSt. & 3.57 & 23 & 1.0 \\
\hline $\mathrm{Fe}+0.8 \%$ ZnSt. & 3.50 & 30 & 1.5 \\
\hline $\mathrm{Fe}+1.2 \%$ ZnSt. & $\mathbf{3 . 4 3}$ & 44 & 2.0 \\
\hline Fe-2\%Cu+0.8\%ZnSt. & 3.39 & 28 & 1.5 \\
\hline Fe-2\%Cu-1\%C+0.8\%ZnSt. & 3.35 & Not flow & 3.5 \\
\hline Pre-mixed powder & 3.16 & 29 & 2.5 \\
\hline
\end{tabular}

から $\phi 6 \mathrm{~mm}$ まで変えたロートで測定した值である. この值が大きいほど流動度は小さい傾向にあり，ほ ほ対応している。

\section{3 実験結果及び考察}

\section{1 薄肉矩形キャビティへの充填}

厚さ $1 \mathrm{~m} \mathrm{~m}$ の矩形キャビティへの $\mathrm{Fe}$ $2 \% \mathrm{Cu}+0.8 \% \mathrm{ZnSt}$. 混合粉の充填過程を Photo. 2 に示 す. 粉箱がキャビティの真上まで前進して来ても, 粉末は一気に落下することはなく, 徐々に流れ落ち て充填した.

粉末による充填過程の違いをPhoto.3に示す.こ れらは粉箱が後退する直前の状態である。 $\mathrm{Fe}+0.8 \% \mathrm{ZnSt}$. 粉ではほほ充填が完了しているが, $\mathrm{Fe}+1.2 \% \mathrm{ZnSt}$. やPre-mix 粉では粉箱が前進する過程 では完全には充填せず, 粉箱が後退する過程で充填 が完了した。またこれらの粉末は粉箱内で棚をつ り，大きな空洞が発生するのが観察された。これに 対し, $\mathrm{Fe}-2 \% \mathrm{Cu}-1 \% \mathrm{C}+0.8 \% \mathrm{ZnSt}$. 混合粉では粉箱が 後退した後も完全には充填しなかった。
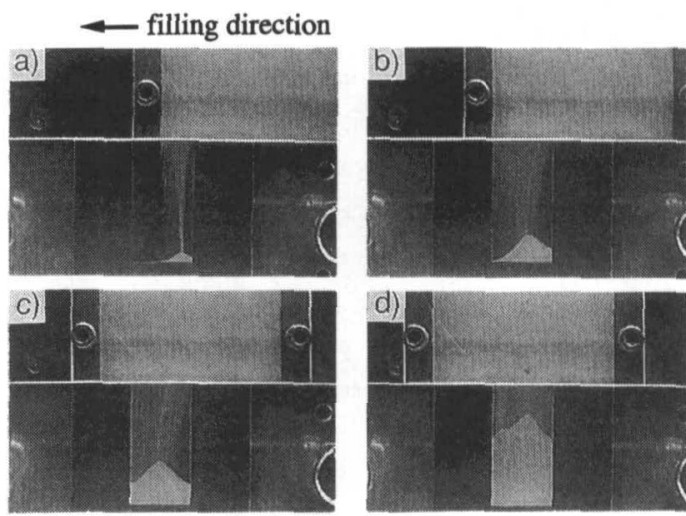

Photo. 2 Continuous video frames of powder filling process in rectangular cavity. (Powder: $\mathrm{Fe}-2 \% \mathrm{Cu}+0.8 \% \mathrm{ZnSt}$.; $\mathrm{t}: 1 \mathrm{~mm}$; V: $60 \mathrm{~mm} / \mathrm{s}$ )

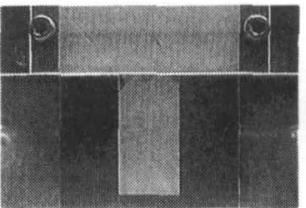

a) $\mathrm{Fe}+0.8 \% \mathrm{ZnSt}$

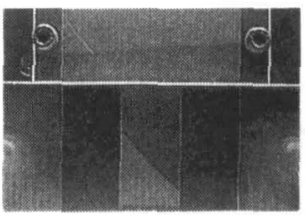

c) $\mathrm{Fe}-2 \% \mathrm{Cu}-1 \% \mathrm{C}+0.8 \% \mathrm{ZnSt}$.

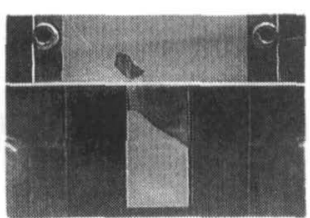

b) $\mathrm{Fe}+1.2 \% \mathrm{ZnSt}$.

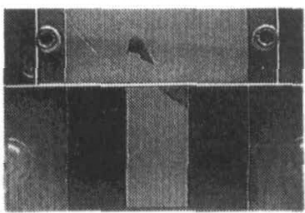

d) Pre-mixed powder
Photo. 3 Difference in filling processes of various powders. ( $\mathrm{t}: 1 \mathrm{~mm} ; \mathrm{V}: 60 \mathrm{~mm} / \mathrm{s}$ ) 
粉箱を $60 \mathrm{~mm} / \mathrm{s}$ の速度で移動させた時の充填密度 に及ぼすキャビティ厚さの影響を Fig. 2 に示す。い ずれの粉末も充填密度は厚さが薄くなるほど低下 し, 厚さが $1 \mathrm{~mm}$ では見掛け密度よりも低かった。 そ の低下度合いは流動性の悪い粉末ほど大きかった。

キャビティ厚さ $(\mathrm{t})$ が $1 \mathrm{~mm}$ と $5 \mathrm{~mm}$ の場合の粉末 の充填状態をPhoto. 4 に示す. 厚さが $1 \mathrm{~mm}$ では充填 された粉末には細粉が多く偏析しているのに対し て, 厚さが $5 \mathrm{~mm}$ では粒度偏析が生じている部分は 認められなかった。

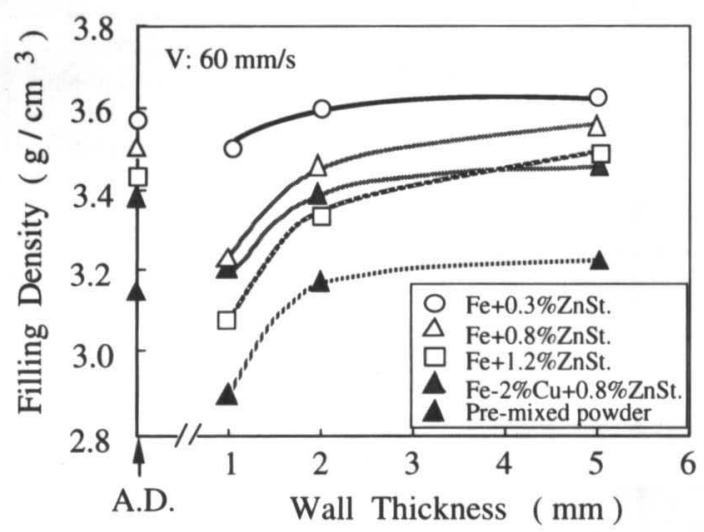

Fig. 2 Effect of wall thickness of rectangular cavity on filling density.

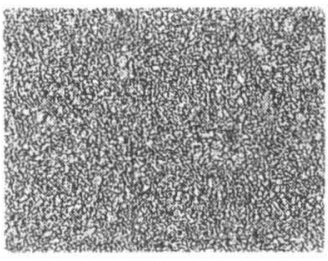

$\mathrm{t}=1 \mathrm{~mm}$

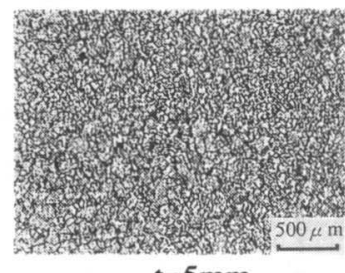

$\mathrm{t}=5 \mathrm{~mm}$
Photo. 4 Photomicrographs of powder filled into rectangular cavity.

( Powder: Fe-2\% Cu+0.8\%ZnSt.; V: $60 \mathrm{~mm} / \mathrm{s}$ )

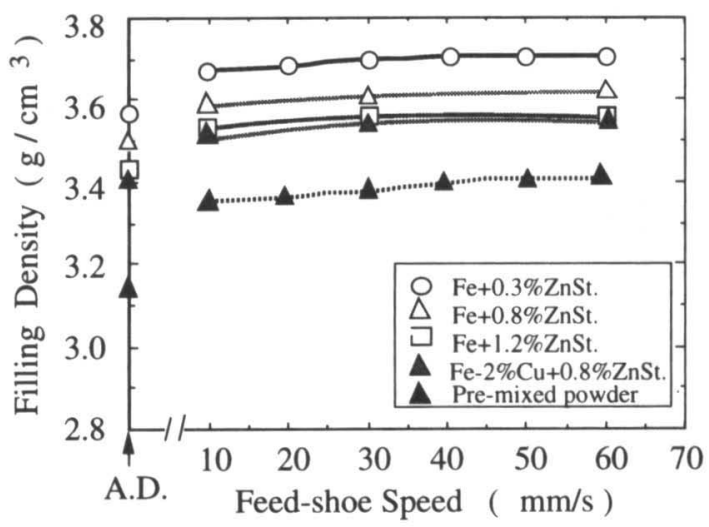

Fig. 3 Effect of feed-shoe speed on filling density in complex cavity.

\section{2 複雑形状キャビティへの充填}

充填密度に及ほすす粉箱移動速度の影響を Fig. 3 に 示す. 充填密度は粉箱の移動速度が大きいほど, い ずれの粉末もわずかに高くなった。またこれらは 見掛密度より $0.1 \sim 0.2 \mathrm{~g} / \mathrm{cm}^{3}$ 高い値であった。

$10 \mathrm{~mm} / \mathrm{s}$ の速度で粉箱を横送りとした場合の粉末 の充填過程をPhoto.5に示す．粉箱がキャビティの 端から数 $\mathrm{mm}$ 突き出た所から粉末の流出が始まる. その後,粉末は粉箱の移動に伴い安息角に沿って斜 面を転がり落ちて順次キャビティを満たす。これに 対して，粉箱速度を $60 \mathrm{~mm} / \mathrm{s}$ とした場合には, Photo.6に示すように, 粉箱の先端が中央部付近に 到達したあたりで, 手前の厚肉部に粉末が一気に落 下する(a). そのためにキャビティ内の空気は激し く押し出され, その後に落下する粉末はこの空気の 流れにより前方へ吹き飛ばされる(b). 薄肉部では 空気と粉末との置換が遅れ, 後から落下した粉末に 空気の逃げ道を塞がれて空洞が発生する(c).この 空洞は徐々に上方へ移動しながら消滅する.その先 の厚肉部では速度が $10 \mathrm{~mm} / \mathrm{s}$ の場合と同様, 安息角 に沿って充填が進行する(d).
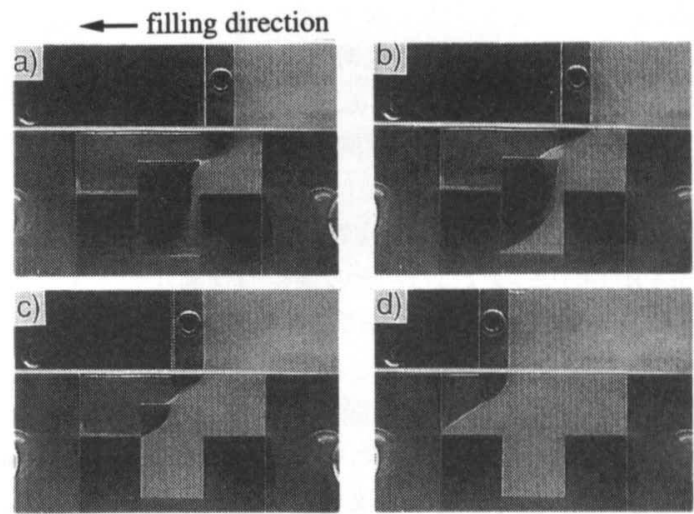

Photo. 5 Continuous video frames of powder filling process in complex cavity.

( Powder: Fe-2\%Cu+0.8\%ZnSt.; V: $10 \mathrm{~mm} / \mathrm{s}$ )
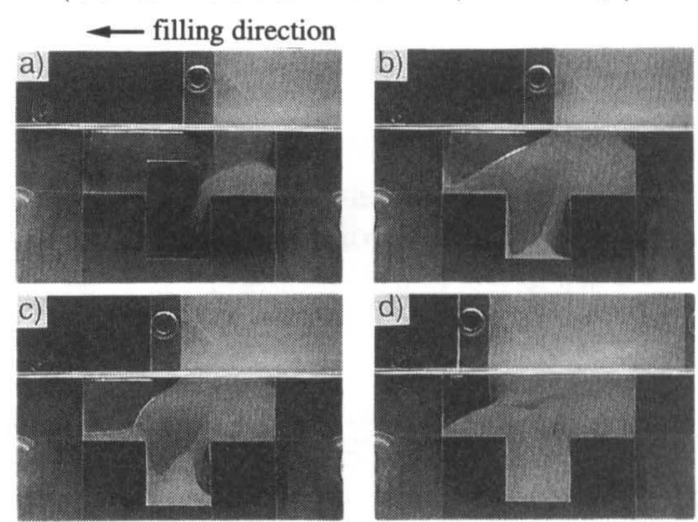

Photo. 6 Continuous video frames of powder filling process in complex cavity.

( Powder: Fe-2\%Cu+0.8\%ZnSt.; V: $60 \mathrm{~mm} / \mathrm{s}$ ) 
$60 \mathrm{~mm} / \mathrm{s}$ の速度で粉箱を正面送りとした場合の充 填過程をPhoto.7 に示す。この場合, 粉箱がキャビ ティ上を移動する距離は $20 \mathrm{~mm}$ である．粉箱がキャ ビティ端から 10 から $15 \mathrm{~mm}$ 突き出たところで一気に 粉末が落下して空気を前方へ押し出す(a). しかし, 薄肉部の空気は置換されず空洞が発生する。その 後, 薄肉部へは両側の上段から粉末が流入して徐々 に充填される $(\mathrm{b}, \mathrm{c})$. 粉箱により上部を塞がれている ため空洞はなかなか消滅しない(d).このように, 粉 箱の移動方向をどちらにしても薄肉部には空洞が発 生した。しかし, 粉箱の速度が $20 \mathrm{~mm} / \mathrm{s}$ 以下では薄 肉部に空洞の発生は認められなかった。

$60 \mathrm{~mm} / \mathrm{s}$ で粉箱を横送りとした場合について, 代 表的な部位における粉末の充填状態をPhoto. 8 に示 す. 最初に粉末が流れ込む段差部では細粉と粗粉が 分離して境界ができている(b). 一方，その反対側の 段差部や薄肉部 (c)および充填過程で発生した空洞 が最終的に消滅する所には細粉が集まり偏析してい た. 細粉は空洞を形成する空気の動きに容易に卷き 込まれることによって生ずるものと考えられる。こ れに対して, 安息角に沿って粉末が流れて充填され る部分では粗粉が多くなった(a).このことは，粉末 のうち転がり易いのは粗粉であることによって発生 すると言える。このような充填状態は, 粉箱の送り 速度が遅い場合や充填方向を変えた場合でも同様に 認められた。

以上の観察結果から, 複雑な形状のキャビティに粉 末を充填する場合には, その過程で空洞が発生するよ うな䇢所には細粉が, 安息角に沿った充填がされる箇 所には粗粉が偏析することが分かった. 通常の混合粉 末では, 銅粉や黒鉛粉は微粉で添加されることから， これらの粉末が偏析すると寸法精度に大きく影響する ことは寸法変化に関する文献 3 ， 4) 加予想される。 ま た, 偏析防止処理がされた粉末であっても, 粒度偏析 が生じれば寸法変化に大きく影響する. 従って, 粉末 と空気との置換を速くさせ空洞の発生を抑えることや 安息角に沿って粉末が流れる様な充填を避けることが 重要である。

\section{4 まとめ}

新しく考案した粉末充填可視化装置を用いて, 落 込み充填における粉末の挙動を調べた結果, 以下の ことが明かとなった。

1. 複雑な形状のキャビティへの充填過程において は, 粉末と空気との置換の遅れによる空洞の発生, 空気の流れによる粉末の飛散や安息角に沿った粉末 の移動によって粒度偏析が生ずる.このような現象 は, キャビティ形状, 粉箱の移動速度および粉末の 流動性の影響を受ける。
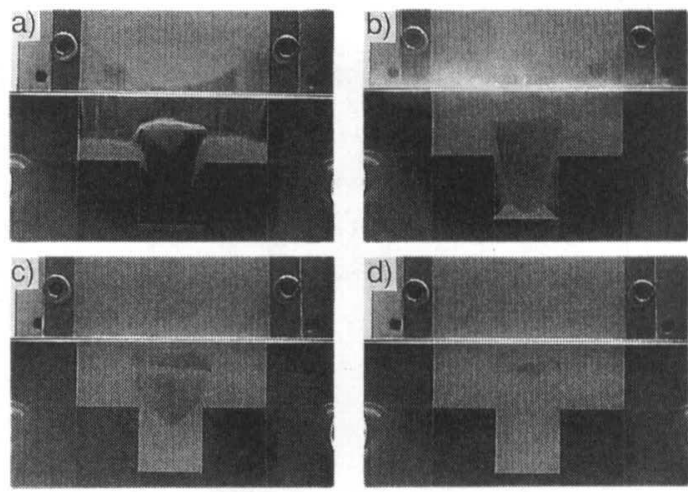

Photo. 7 Continuous video frames of powder filling process in complex cavity when feed-shoe moves back and forth.

( Powder: Fe-2\% Cu+0.8\%ZnSt.; V: $60 \mathrm{~mm} / \mathrm{s}$ )
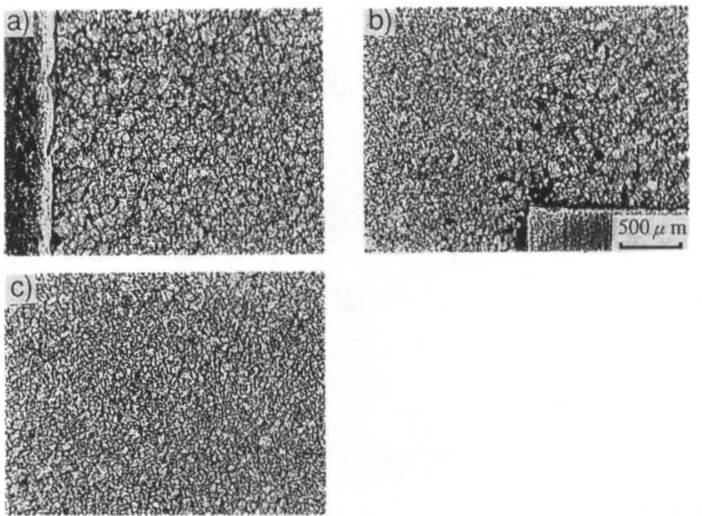

Photo. 8 Photomicrographs of filled powder in complex cavity when feed-shoe moves transversely.

( Powder: Fe-2\% Cu+0.8\%ZnSt.; V: $60 \mathrm{~mm} / \mathrm{s}$ )

2. 薄肉部やそこに発生する空洞が最終的に消滅する 箇所および空気に飛ばされた粉末が堆積する箇所に は細粉が偏析し, 安息角に沿って粉末が流れる箇所 には粗粉が偏析する。

3. 単純な矩形キャビティでも薄肉になるほど細粉の 偏析が顕著に生じる。また, 充填密度も低下し，そ の度 合いは流動性の悪い粉末ほど大きい。

\section{文 献}

1) 大石芳宏, 久保田毅, 浅井満, 木村尚, 犬飼敏昭, 宇野和夫：粉体粉末治金協会, 昭和 53 年度秋季 大会講演概要集 (1978), 6.

2) E.R.Rice, J.Tengzelius:Powder Met., 29(1986) 183.

3) S.Masuhara, S.Kawai : Adv. Powder Met. 3 (1992) 267

4) V.Arnhold, H.Rapp, R. Wahling :Adv. Powder Met. 3 (1994) 237. 